\title{
RELIABILITY DESIGN OF BREAKWATER ARMOR BLOCKS CONSIDERING VARIABILITY IN WAVE DIRECTION IN COMPUTATION OF WAVE TRANSFORMATION
}

\author{
KYUNG DUCK SUH \\ School of Civil, Urban and Geosystem Engineering \& Research Institute of Marine Systems \\ Engineering, Seoul National University, San 56-1, Shinlim-Dong, Gwanak-Gu, Seoul 151-742, \\ Korea, E-mail: kdsuh@snu.ac.kr \\ HYUCK-MIN KWEON \\ Department of Civil Engineering, Kyongju University, San 42-1, Hyohyun-Dong, Kyongju-Si, \\ Kyongsangbuk-Do 780-210, Korea, E-mail: hmkweon@kyongju.ac.kr \\ HYUN DEOK YOON \\ Hanah Engineering Co., Ltd., Kwansesa Bldg., 4Fl., 209-9 Nonhyun-Dong, Kangnam-Gu, Seoul \\ 135-010,Korea,E-mail: hdoug@hanah.co.kr
}




\begin{abstract}
Recently Hanzawa et al. developed a reliability design method for the calculation of the expected damage level of armor blocks of a horizontally composite breakwater. In their method, the wave transformation from deepwater to the design site was calculated by assuming unidirectional random waves being normally incident to a straight coast with parallel depth contours. In real situations, however, directional random waves with variable principal wave directions will be incident to the shore of irregular bathymetry. In the present study, the reliability design method of Hanzawa et al. was extended to take into account the variability in wave direction in the computation of wave transformation. The directional variability includes directional spreading of waves, obliquity of the design principal wave direction from the shore-normal direction, and its variation about the design value. Even though the wave incident angle to the breakwater could be calculated, normal incidence was assumed in the calculation of the damage level of armor blocks. It was found that the inclusion of directional variability in the computation of wave transformation had great influence on the computed expected damage level of armor blocks. The previous design, which disregarded wave directionality, could either overestimate or underestimate the expected damage level by a factor of two depending on water depth and seabed slope.
\end{abstract}

Keywords: Armor blocks, breakwaters, expected damage level, reliability design, variability in wave direction 


\section{Introduction}

Reliability design methods have been developed for breakwater designs since the mid-1980s, especially in Europe and Japan. In Europe, van der Meer (1988a) proposed a probabilistic approach for the design of breakwater armor layers, and Burcharth (1991) introduced the partial safety factors in the reliability design of rubble mound breakwaters. Recently Burcharth and Sørensen (1999) established partial safety factor systems for rubble mound breakwaters and vertical breakwaters by summarizing the results of the PIANC (Permanent International Association of Navigation Congresses) Working Groups. The European reliability design methods belong to what is called as Level 2 method. On the other hand, in Japan Level 3 reliability design methods have been developed, in which the expected sliding distance of a caisson of a vertical breakwater (Shimosako and Takahashi, 1999; Goda and Takagi, 2000) or the expected damage level of armor blocks of a horizontally composite breakwater (Hanzawa et al., 1996) during their lifetime is estimated. Monte Carlo simulations are used to take into account the uncertainties of various design factors. The Level 2 method with partial safety factors is easier for engineers to use, but the Level 3 method gives generally more useful design information.

In the Japanese reliability design methods, the wave transformation from deepwater to the location of the breakwater is calculated by assuming unidirectional random waves being normally incident to a straight coast with parallel depth contours. Wave attenuation by random breaking is evaluated with Goda's (1975) model. In real situations, however, directional random waves with variable principal wave directions will be incident to the shore, undergoing refraction as well as shoaling and breaking. Ignoring the variability in wave direction, wave heights may be overestimated at the location of the breakwater and consequently the breakwater will be over-designed. Takayama and Ikeda (1993) reported that in order to correct this overestimation, the significant and maximum wave heights need reduction of $6 \%$ and $13 \%$, respectively. A more realistic wave transformation model, however, should be used to more accurately compute the shallow water waves by taking into account the variability in wave direction.

In the present study, we extend the Level 3 reliability design method developed by Hanzawa et al. (1996) to take into account the variability in wave direction. The directional variability includes directional spreading of random directional waves, obliquity of the design principal wave direction from the shore-normal direction, 
and its variation about the design value. To calculate the transformation of random directional waves over an arbitrary bathymetry including surf zones, we used Kweon et al.'s (1997) model, which was developed by combining Kweon and Goda's (1996) breaking wave model and Karlsson's (1969) spectral wave refraction model. The model was verified by comparison with Goda's (1975) results for unidirectional random waves on a plane beach and with the experimental data of Vincent and Briggs (1989) for the transformation of random directional waves over a shoal.

In the following section, the computational procedure for estimating the expected damage level of breakwater armor blocks is described. In section 3, the variability in wave direction off the east coast of the Korean peninsula is analyzed. In section 4, several computational examples are presented to compare the results of the present study with those of previous authors and to illustrate the importance of wave directionality. Major conclusions and a proposal of future studies then follow.

\section{Computational Procedure}

The basis of the reliability design method is to consider the stochastic behaviors of loads and resistances. As described in the introduction, in the present study we employ the Level 3 design method, which introduces the probability density functions of design factors. Use of random variation in design factors is explained below in conjunction with the computational flow chart sketched in Fig. 1.

\subsection{Offshore waves}

Damage to breakwater armor blocks is in general caused by large waves comparable to design waves. Therefore the annual maximum offshore wave height is considered sufficient to be incorporated into the calculation. The offshore wave height is usually determined by referring to the extreme wave height distribution, which is constructed using the extreme wave data of long-term observations or hindcasts. In the present study, the following Weibull distribution function was employed for the annual maximum wave heights: 


$$
F(x)=1-\exp \left\{-\left[\frac{x-B}{A}\right]^{k}\right\}
$$

where $x$ stands for the annual maximum significant wave height, $A$ and $B$ are the scale and location parameters, respectively, and $k$ is the shape parameter. An annual maximum significant wave height is randomly sampled from the distribution function and is denoted as $H_{0 e}$. This wave height is further given a stochastic variation with the normal distribution having a mean $H_{0}$ and standard deviation $\sigma_{H_{0}}$. This variation represents the uncertainty in the estimate of the extremal distribution function owing to the limited sample size of extreme wave data or the inaccuracy in wave hindcasts. The mean wave height and the standard deviation are assumed to have the following relations with $H_{0 e}$ (Takayama and Ikeda, 1994):

$$
H_{0}=\left(1+\alpha_{H_{0}}\right) H_{0 e}, \quad \sigma_{H_{0}}=\gamma_{H_{0}} H_{0 e}
$$

where $\alpha_{H_{0}}$ and $\gamma_{H_{0}}$ denote the bias and deviation coefficients, respectively. The sample offshore wave height $H_{0 c}$ to be used in the calculation is then determined by a normalized random number based on Eq. (2). The corresponding significant wave period is determined to yield a constant wave steepness ( 0.03 in this study) offshore:

$$
T_{s}=\left(\frac{2 \pi H_{0 c}}{0.03 g}\right)^{1 / 2}
$$

where $g$ is the gravitational acceleration.

Offshore random directional waves with the directional spreading parameter $s_{\max }$ are assumed to be incident with the principal wave direction $\left(\alpha_{p}\right)_{0}$ with respect to the shore-normal direction. The principal wave direction is assumed to have a stochastic variation with the normal distribution having a mean being the 
same as the design principal wave direction $\left(\alpha_{p}\right)_{0 d}$ and a standard deviation $\sigma_{\left(\alpha_{p}\right)_{0}}$. Unidirectional random waves normally incident to the shore are simulated by setting $s_{\max }=\infty, \sigma_{\left(\alpha_{p}\right)_{0}}=0$ and $\left(\alpha_{p}\right)_{0 d}=0$.

The offshore directional wave spectrum is expressed as

$$
S_{0}(f, \theta)=S_{0}(f) G(\theta \mid f)
$$

where $f$ and $\theta$ denote the wave frequency and angle, respectively, $S_{0}(f)$ is the Bretschneider-Mitsuyasu frequency spectrum given by

$$
S_{0}(f)=0.205 H_{0 c}^{2} T_{s}^{-4} f^{-5} \exp \left[-0.75\left(T_{s} f\right)^{-4}\right]
$$

and $G(\theta \mid f)$ is the directional spreading function given by

$$
G(\theta \mid f)=G_{0} \cos s^{s}\left(\frac{\theta}{2}\right)
$$

In the preceding equation, $G_{0}$ is a constant given by

$$
G_{0}=\frac{1}{\pi} 2^{2 s-1} \frac{\Gamma^{2}(s+1)}{\Gamma(2 s+1)}
$$

where $\Gamma$ denotes the Gamma function. The spreading parameter $s$ is related to its peak value $s_{\max }$ as

$$
s= \begin{cases}\left(f / f_{p}\right)^{5} s_{\text {m a x }} & f \leq f_{p} \\ \left(f / f_{p}\right)^{-2.5} s_{\text {m a x }} & f \geq f_{p}\end{cases}
$$

where $f_{p}$ denotes the frequency at the spectral peak and is related to the significant wave period as $f_{p}=1 /\left(1.05 T_{s}\right)$ for the case of the Bretschneider- 
Mitsuyasu frequency spectrum.

\subsection{Wave transformation}

The variation in water level by tide is assumed to have a sinusoidal variation between the design water level (e.g. LWL) and the water level increased by the tidal range (e.g. HWL). A sample of the tidal elevation $\eta$ with respect to the mean water level is determined based on this assumption using a random number uniformly distributed between 0 and $2 \pi$ as the phase of the sinusoidal curve.

As offshore waves propagate toward the design site, they undergo various shallow water wave transformation processes. In the present study, we use the Kweon et al.'s (1997) model to calculate the transformation of random directional waves. Given the offshore directional wave spectrum and water level, the model calculates the directional spectrum at each grid point in the model domain, from which the significant wave height and principal wave direction are obtained. The model includes most of the shallow water wave transformation processes except reflection and diffraction.

The wave height at the design site $H_{1 / 3 e}$, calculated by the Kweon et al's (1997) model, is also assumed to have computational uncertainty, and thus is given stochastic variation with the normal distribution as with the offshore wave height. The mean $H_{1 / 3}$ and the standard deviation $\sigma_{H_{1 / 3}}$ are assumed to have the following relations with $H_{1 / 3 e}$ :

$$
H_{1 / 3}=\left(1+\alpha_{H_{1 / 3}}\right) H_{1 / 3 e}, \quad \sigma_{H_{1 / 3}}=\gamma_{H_{1 / 3}} H_{1 / 3 e}
$$

where $\alpha_{H_{1 / 3}}$ and $\gamma_{H_{1 / 3}}$ denote the bias and deviation coefficient, respectively. The sample wave height at the design site $H_{1 / 3 c}$ is determined by a normalized random number based on Eq. (9).

The Kweon et al.'s (1997) model computes the principal wave direction as well as the wave height at the design site. Theoretically, therefore, we could include the effect of oblique wave attacks on the damage of breakwater armor blocks. However, all the stability formulas for breakwater armor blocks proposed up to date assume waves normally incident to the breakwater, even though there are 
several studies on the influence of wave directionality on breakwater armor blocks (Losada and Giménez-Curto, 1982; Christensen et al., 1984; Matsumi et al., 1994; $\mathrm{Ryu}, 2001)$. Therefore, we assume that the waves are incident normally to the breakwater in the calculation of the damage level of armor blocks. The calculated damage level, however, will be different from that obtained using the Goda's (1975) model because in our model the wave directionality has been included in the computation of wave transformation.

\subsection{Computation of damage level of armor blocks}

In the reliability design of breakwater armor blocks, the expected total damage level during the lifetime of the breakwater is aimed to be smaller than an allowable design damage level. In order to estimate the damage level of the armor blocks of a horizontally composite breakwater, the following stability formula proposed by Hanzawa et al. (1996) for Tetrapods was used:

$$
N_{S}=\frac{H_{1 / 3}}{\Delta D_{n}}=2.32\left(\frac{N_{0}}{N^{0.5}}\right)^{0.2}+1.33
$$

where $N_{S}$ is the stability number, $\Delta$ the relative mass density of the armor block in water $\left(=\rho_{s} / \rho-1 ; \rho_{s}=\right.$ mass density of the block, $\rho=$ mass density of water $), D_{n}$ the nominal diameter of the block $\left(=V^{1 / 3} ; V=\right.$ volume of the block), $N_{0}$ the relative damage level defined by van der Meer (1988b) as the actual number of displaced blocks within the width (along the breakwater alignment) of one nominal diameter $D_{n}$, and $N$ the number of waves during a storm. This equation can be rewritten to estimate the damage level as

$$
N_{0}=\left(\frac{\frac{H_{1 / 3}}{\Delta D_{n}}-1.33}{2.32}\right)^{5} N^{0.5}
$$

Damage to the armor blocks was assumed to occur under rough sea conditions 
of the wave height of design level $\left(H_{c r i}\right)$ or greater in a cumulative way over the lifetime of the breakwater. $H_{c r i}$ is defined as the wave height corresponding to $N_{0}=0$ in Eq. (10), or $H_{c r i}=1.33 \Delta D_{n}$. The accumulation of damage is calculated by Hanzawa et al.'s (1996) method, which is summarized below. Supposing the wave height at the breakwater for the $i$ th year is $H_{1 / 3 c}(i)$ and the total damage level up to the $(i-1)$ th year is $N_{0}(i-1)$, the number of waves which attacked the breakwater up to the $(i-1)$ th year, $N^{\prime}$, is determined using $H_{1 / 3 c}(i)$ and $N_{0}(i-1)$ respectively in place of $H_{1 / 3}$ and $N_{0}$ in the following equation derived from Eq. (10):

$$
N^{\prime}=\left(\frac{\frac{H_{1 / 3}}{\Delta D_{n}}-1.33}{2.32}\right)^{-10} N_{0}^{2}
$$

The total damage level up to the $i$ th year, $N_{0}(i)$, is calculated by Eq. (11) with $N=N^{\prime}+N(i)$ and $H_{1 / 3}=H_{1 / 3 c}(i)$. The first estimation of the damage level during the $i$ th year is calculated as $\Delta N_{0}=N_{0}(i)-N_{0}(i-1)$. Taking into account the uncertainty of damage, this damage level is further given a stochastic variation with the normal distribution with the mean $\Delta N_{0}$ and the standard deviation $\sigma_{\Delta N_{0}}$. Analyzing the experimental data of Tanimoto et al. (1985), Hanzawa et al. (1996) proposed the relation between $\Delta N_{0}$ and $\sigma_{\Delta N_{0}}$ as

$$
\sigma_{\Delta N_{0}}=0.36 \Delta N_{0}^{0.5}
$$

The sample data of $\Delta N_{0 c}$ was determined by the normalized random number with the standard deviation defined by the preceding equation. The damage level up to the $i$ th year is finally calculated as $N_{0}(i)=N_{0}(i-1)+\Delta N_{0 c}$.

The method described above is the procedure for calculating the damage level up to a certain year, and the total damage level accumulated within one lifetime is calculated by repeating this process up to the lifetime of the breakwater. The process of one lifetime cycle is shown in Fig. 1. This process is repeated 2,000 
times, and the total accumulated damage levels thus obtained are added together and divided by 2,000 to yield the expected total damage level. The number, 2,000, was chosen based on Hanzawa et al. (1996), who have shown that a stable statistical result can be obtained by doing so.

\section{Analysis of Variability in Principal Wave Direction}

In order to get some idea of the variability in principal wave direction in the field, we analyzed the wave hindcasting data provided on the homepage of the Korea Ocean Research and Development Institute (http://www.kordi.re.kr). The deepwater wave hindcasting was made every three hours for 20 years (from 1979 till 1998) using the HYPA (HYbrid PArametrical) model and the ECMWF (European Center for Medium-range Weather Forecasts) wind data. The grid size was about $27 \mathrm{~km}$. The site provides statistical data including significant wave height and period, principal wave direction, and directional wave spectrum at 67 locations around South Korea as shown in Fig. 2. Among these we used the data at the locations along the east coast of Korea, or those from 53 to 67 (excluding 57 and 60) as shown in Fig. 2, where the coast is relatively simple, the tidal range is very small (i.e. several tens of centimeters), and waves from northeast direction are dominant.

In Table 1, for 16-point bearings, are given the number of occurrence of waves greater than $3 \mathrm{~m}$ of significant wave height at each location. The average principal wave direction measured clockwise from the north, that measured counterclockwise from the shore-normal direction, and the standard deviation are also presented for each location. The shoreline lies North to South for the locations from 53 to 58 , and it is inclined $30^{\circ}$ from the north-south direction for those from 59 to 67 (see Fig. 2). The average principal wave direction is almost constant at about $42^{\circ}$ up to the location 61 , and after that, it turns east for more northerly locations. The standard deviation changes to give a slightly larger value as one moves southward, probably because of the effect of typhoons. The average principal wave direction with respect to the shore-normal direction shows two relatively constant values at the locations from 53 to 58 and from 62 to 64 . Notably, at the locations from 53 to 58 , the principal wave direction is largely deviated from the shore-normal direction with a relatively large standard deviation, indicating that the influence of wave directionality on the estimation of shallow water wave 
heights may be important.

\section{Illustrative Examples}

In this section, we present several computational examples to compare our results with those of previous authors and to illustrate the importance of wave directionality. Even though the Kweon et al.'s (1997) model is capable of computing the transformation of random directional waves on irregular bathymetry, hereinafter we consider only a plane beach, which is simple but sufficient to illustrate the influence of wave directionality. The common computational conditions are given below.

The Weibull distribution function with $k=2.0, A=2.23$, and $B=4.78$ was used as the extreme distribution of the offshore wave height, which gave a design deepwater wave height, with a return period of 50 years, to be $9.2 \mathrm{~m}$. The deepwater wave steepness was assumed to be constant at 0.03 so that the corresponding design wave period was $14.0 \mathrm{~s}$. The parameters expressing the uncertainties for the offshore wave height were $\alpha_{H_{0}}=0.0$ and $\gamma_{H_{0}}=0.1$. The number of waves was set to 1,000 for all the computations. A tidal range of $1.0 \mathrm{~m}$ was assumed. Seabed slopes of 1/50 and 1/10 were employed. Water depths of 7, 9, $11,13,15,17,19$, and $21 \mathrm{~m}$ at LWL were examined. The design wave height at each water depth was determined by computing the wave heights corresponding to $H_{0}=9.2 \mathrm{~m}$ while changing the water level from LWL to HWL and taking the largest wave height. The mass of a Tetrapod was calculated by Eq. (10) under the criteria of $N_{0}=0.3$ and $N=1000$ against the design wave height at each water depth.

\subsection{Unidirectional random waves normally incident to plane beach}

Hanzawa et al. (1996) computed the expected damage level of the Tetrapods of a horizontally composite breakwater exposed to unidirectional random waves normally incident to a plane beach using Goda's (1975) model. On the other hand, Kweon et al. (1997) simulated the unidirectional random waves on a plane beach by setting the directional spreading parameter $s_{\max }$ to be 1,000 in their threedimensional random breaking wave model, showing that their results were in good 
agreement with Goda's. Herein we used Kweon et al.'s model to compute the wave transformation, and compared the calculated expected damage level of the Tetrapods with Hanzawa et al.'s results. It was expected that these two results would not show much difference because the wave models used gave similar results. The parameters expressing the uncertainties in the computation of wave transformation were $\alpha_{H_{1 / 3}}=-0.13$ and $\gamma_{H_{1 / 3}}=0.09$ as with Hanzawa et al.

The design wave heights and masses of Tetrapods at different water depths are given in Table 2. In general both values are a little greater than those of Hanzawa et al.'s (1996) paper for the seabed slope of 1/10, while they are a little smaller for the slope of 1/50, due to a difference in the wave transformation models used. Fig. 3 shows a comparison of the expected damage level at different water depths between the present model and Hanzawa et al.'s (1996) model. There is a small difference observed between the two models, but the overall trends are similar, as expected.

Hanzawa et al. (1996) used the bias for the wave transformation $\alpha_{H_{1 / 3}}=-0.13$. According to Takayama and Ikeda (1993), the bias in Goda's (1975) model is reported as -0.06 for the significant height and -0.13 for the maximum height. Since the significant height is used in the design of rubble mound breakwaters, therefore, it may be more reasonable to use $\alpha_{H_{1 / 3}}=-0.06$.

Fig. 4 shows a comparison between the results of $\alpha_{H_{1 / 3}}=-0.13$ and $\alpha_{H_{1 / 3}}=-0.06$. The trend with respect to the water depth is the same for each seabed slope, but the damage level with $\alpha_{H_{1 / 3}}=-0.06$ is about twice that with $\alpha_{H_{1 / 3}}=-0.13$

\subsection{Examination of influence of variation in wave direction}

The primary purpose of the present study is to examine the influence of the directional variability upon the computation of the expected damage level of armor blocks, which was not included in Goda's (1975) model. For this purpose, we 
carried out the computation for the six cases listed in Table 3.

Case 1 is for unidirectional waves normally incident to the beach as in Goda's (1975) model. Case 2 includes the effect of directional spreading. The spreading parameter $s_{\max }$ equal to 20 was used, which corresponds to the deepwater wave steepness of 0.03 (Goda, 2000, p. 35). Case 3 is for unidirectional waves incident at $20^{\circ}$ with respect to the shore-normal direction, including only the effect of wave refraction. Case 4 examines the effect of the variation in the principal wave direction. $\left(\alpha_{p}\right)_{0 d}=0^{\circ}$ and $\sigma_{\left(\alpha_{p}\right)_{0}}=15^{\circ}$ were used. For these cases, $\alpha_{H_{1 / 3}}=-0.06$ and $\gamma_{H_{1 / 3}}=0.09$ were used. In Cases 2 to 4 , however, is included a fraction of the effects of refraction and directional spreading that were ignored in Goda's (1975) model. Therefore, the bias must be smaller than -0.06 , say -0.04 . However, how small was uncertain, so the value of -0.06 was used without change. Case 5 included all of the directional variability partly considered in Cases 2 to 4 . Case 6 represented the conditions at the locations 53 to 58 in Fig. 2 (see also Table 1). In Cases 5 and 6, all of the directional variability was included, so no bias was assumed in the computation of wave transformation, i.e., $\alpha_{H_{1 / 3}}=0.0$ was used.

However, the computational error must still exist, so $\gamma_{H_{1 / 3}}=0.09$ was kept the same.

Fig. 5 shows the variation of wave height with water depth for $s_{\max }$ of 1,000 and 20. As expected, the height of the waves with directional spreading is smaller than that of the unidirectional waves. However, in the shallower part of the beach with a slope of $1 / 50$, the difference is immaterial probably because the effect of directional spreading disappears as the waves propagate toward the shore on a mildly sloping beach.

Fig. 6 shows a comparison of the expected damage level at different water depths between Case 1 and 2. Because the height of the directional waves is smaller than that of the unidirectional waves as shown in Fig. 5, the expected damage level for Case 2 is smaller than that of Case 1. The difference of expected damage level between the two cases becomes smaller as water depth decreases, as does the difference in wave height shown in Fig. 5. One may wonder why the expected damage level shows considerable differences in smaller water depths on the beach of 1/50 slope, whereas the variation of wave height with $s_{\max }$ in 
shallow water $\left(d / H_{0}{ }^{\prime} \leq 1.3\right)$ is inappreciable as shown in Fig. 5. Fig. 5 was constructed using a constant deepwater wave height of $9.2 \mathrm{~m}$ and varying water depths. In the water depth of $7.0 \mathrm{~m}, d / H_{0}{ }^{\prime}$ is equal to 0.76 and thus the influence of $s_{\max }$ on the wave height variation and the damage of armor blocks must be negligible on the 1/50 slope. In the calculation of the damage of armor blocks, however, the deepwater wave height varied, with its design value of 50year return period of $9.2 \mathrm{~m}$. It could be as small as about $4.0 \mathrm{~m}$ so that $d / H_{0}{ }^{\prime}$ became 1.75 in the water depth of $7.0 \mathrm{~m}$. For this value of $d / H_{0}{ }^{\prime}$, the variation of wave height with $s_{\max }$ would be significant so that the difference of damage could be large.

Fig. 7 shows a comparison between Case 1 and 3. The height of obliquely incident waves is smaller than that of normally incident waves owing to wave refraction. Thus the damage level in Case 3 is smaller than that of Case 1. Fig. 8 shows a comparison between Case 1 and 4. Again due to the effect of wave refraction, the damage level in Case 4 is computed to be smaller than that of Case 1.

Fig. 9 shows a comparison between Case 1 and 5. In contrast to Cases 2 to 4, the expected damage level of Case 5 is greater than that of Case 1 except for the larger water depths of the seabed slope of $1 / 10$, where the difference is very small. Also the difference in the expected damage level increases with decreasing water depth for the slope of 1/50; this is different from Cases 2 to 4 where the difference decreases or remains constant with decreasing water depth. Noting that $\alpha_{H_{1 / 3}}$ was -0.06 and 0.0 in Case 1 and 5, respectively, the use of $\alpha_{H_{1 / 3}}=-0.06$ seems to reduce the wave height too much in this case compared with the computation taking all the directional variability into account. In principle, however, the appropriateness of the use of $\alpha_{H_{1 / 3}}=-0.06$ should be examined based on the comparison of measured and calculated wave heights.

Fig. 10 shows a comparison between Case 1 and 6. Except for the smaller water depths of the seabed slope of 1/50, the expected damage level of Case 6 is smaller than that of Case 1. Compared to Case 5, the design principal wave direction is much larger and the standard deviation is also a little larger in Case 6, so a greater influence of wave refraction is expected. This influence can be observed by comparing the results of Cases 5 and 6 . In deeper water and in the 
area of the steeper seabed slope, the difference between Case 5 and 6 is significant because wave refraction is still important. However, the difference becomes smaller in shallower water with a milder seabed slope where the wave breaking effect dominates wave refraction.

Since the above discussions on the difference of expected damage levels are mainly based on the difference of wave heights, it may be instructive to examine the wave height distributions at several water depths. In Table 4, for each case are given the numbers of occurrence of $H_{1 / 3 c}$ in different ranges of $H_{1 / 3 c}$ in the water depth of $9 \mathrm{~m}$ on the beach with a slope of $1 / 50$. The total number of occurrence for each case is 100,000 , that is obtained by 2,000 simulations of 50year lifetime of the breakwater. Fig. 11 shows the ratios of the number of occurrence of $H_{1 / 3 c}$ for each case to that of Case 1 in different ranges of $H_{1 / 3 c}$. The value for each range was plotted at the midpoint of the range (e.g., at 2.5 for the range of 2.0 to $3.0 \mathrm{~m}$ ). Fig. 11 indicates that the ratios of the number of occurrence of $H_{1 / 3 c}$ of Cases 2 to 4 to that of Case 1 are greater than 1.0 for smaller values of $H_{1 / 3 c}$ but smaller than 1.0 for larger values of $H_{1 / 3 c}$. This means that the wave heights in Cases 2 to 4 are on the whole smaller than those in Case 1, explaining why the expected damage levels of Cases 2 to 4 are smaller than that of Case 1 for the water depth of $9 \mathrm{~m}$ and the seabed slope of 1/50. On the other hand, the ratios of the number of occurrence of $H_{1 / 3 c}$ of Case 5 to that of Case 1 are smaller than 1.0 for smaller value of $H_{1 / 3 c}$ and greater than 1.0 for larger values of $H_{1 / 3 c}$, except for the range of 2.0 to $3.0 \mathrm{~m}$, for which, though, the number of occurrence is very small. This means that the wave heights in Case 5 are on the whole larger than those in Case 1, explaining why the expected damage level of Case 5 is greater than that of Case 1. A similar explanation could be made for Case 6.

Table 5 and Fig. 12 show the similar results as Table 4 and Fig. 11, but in the water depth of $19 \mathrm{~m}$. Similar trends as those of the water depth of $9 \mathrm{~m}$ are observed for Cases 2 to 4. The ratios of the number of occurrence of $H_{1 / 3 c}$ of Case 5 to that of Case 1 are close to unity except the ranges of 2.0 to $4.0 \mathrm{~m}$ and 12.0 to 13.0 $\mathrm{m}$, for which, though, the number of occurrence is relatively small. Therefore, the difference of the expected damage level between Case 1 and 5 is small as shown in Fig. 9. On the other hand, the ratios of the number of occurrence of $H_{1 / 3 c}$ of Case 6 to that of Case 1 are greater than 1.0 for smaller value of $H_{1 / 3 c}$ and smaller than 1.0 for larger values of $H_{1 / 3 c}$. This means that the wave heights in Case 6 are on the whole smaller than those in Case 1, explaining why the expected damage 
level of Case 6 is smaller than that of Case 1.

In summary, for a more reasonable estimation of the wave height in shallow water, it is necessary to compute the wave transformation taking into account the variability in wave direction rather than correcting the wave height by using a constant bias $\alpha_{H_{1 / 3}}$. It was also observed that the previous designs, which disregarded wave directionality (as in the calculation of Case 1), could largely overestimate or underestimate the expected damage level depending on water depth and seabed slope. However, this observation is based on the assumption that the waves are normally incident to the breakwater. In order to more precisely take into account the effect of wave directionality, a stability formula for obliquely incident waves should be developed.

\section{Conclusions and Proposals for Future Studies}

In this study, the Level 3 reliability design method developed by Hanzawa et al. (1996) for calculating the expected damage level of armor blocks in a horizontally composite breakwater was extended to take into account the variability in wave direction. It was found that the inclusion of the variability in wave direction had great influence on the computed results of the expected damage level of armor blocks. The previous design, which disregarded wave directionality in the computation of wave transformation, could either overestimate or underestimate the expected damage level by a factor of two depending on water depth and seabed slope.

In this study, only plane beaches were examined to compare the results with those of previous authors. However, the method developed in this study could be applied to a real beach because Kweon et al.'s (1997) model used in this study is capable of computing the transformation of random directional waves over an arbitrary bathymetry including surf zones. Also, the method developed in this study for a horizontally composite breakwater could be applied to a rubble mound breakwater if a proper stability formula of armor blocks is provided. It also could be used for the calculation of the expected sliding distance of caissons in a vertical breakwater. The latter may be interesting, in particular, because Goda's (2000) pressure formula includes the effect of wave angle at the breakwater, which can be calculated using Kweon et al.'s (1997) model. Finally, in order to more precisely 
take into account the effect of wave directionality on the stability of armor blocks, a reliable stability formula for oblique incident waves should be developed, like Goda's pressure formula for a vertical breakwater.

\section{Acknowledgement}

This work was supported by the Brain Korea 21 Project.

\section{References}

Burcharth, H. F. (1991). Introduction of partial coefficient in the design of rubble mound breakwaters. Proc. Conf. on Coastal Structures and Breakwaters, Inst. of Civil Engrs., London, pp. 543-565.

Burcharth, H. F. and Sørensen, J. D. (1999). The PIANC safety factor system for breakwaters. Proc. Int. Conf. Coastal Structures '99, A. A. Balkema, Spain, pp. 1125-1144.

Christensen, F. T., Broberg, P. C., Sand, S. E. and Tryde, P. (1984). Behaviour of rubble-mound breakwater in directional and uni-directional waves. Coastal Engrg. 8: 265-278.

Goda, Y. (1975). Irregular wave deformation in the surf zone. Coastal Engrg. Japan 18: 13-26.

Goda, Y. (2000). Random Seas and Design of Maritime Structures, 2nd edn., World Scientific, Singapore, 443p.

Goda, Y. and Takagi, H. (2000). A reliability design method of caisson breakwaters with optimal wave heights. Coastal Engrg. J. 42: 357-387.

Hanzawa, M., Sato, H., Takahashi, S., Shimosako, K., Takayama, T. and Tanimoto, K. (1996). New stability formula for wave-dissipating concrete blocks covering horizontally composite breakwaters. Proc. 25th Int. Conf. on Coastal Engrg., American Soc. of Civil Engrs., Orlando, pp. 1665-1678.

Karlsson, T. (1969). Refraction of continuous ocean wave spectra. J. Waterways and Harbors Div., Proc. American Soc. of Civil Engrs. 95: 437-448.

Kweon, H.-M. and Goda, Y. (1996). A parametric model for random wave deformation by breaking on arbitrary beach profiles. Proc. 25th Int. Conf. on Coastal Engrg., American Soc. of Civil Engrs., Orlando, pp. 261-274.

Kweon, H.-M., Sato, K. and Goda, Y. (1997). A 3-D random breaking model for 
directional spectral waves. Proc. 3rd Int. Symp. on Ocean Wave Measurement and Analysis, American Soc. of Civil Engrs., Norfolk, pp. 416-430.

Losada, M. A. and Giménez-Curto, L. A. (1982). Mound breakwaters under oblique wave attack; A working hypothesis. Coastal Engrg. 6: 83-92.

Matsumi, Y., Mansard, E. P. D. and Rutledge, J. (1994). Influence of wave directionality on stability of breakwater heads. Proc. 24th Int. Conf. on Coastal Engrg., American Soc. of Civil Engrs., Kobe, pp. 1397-1411.

Ryu, C.-R. (2001). The state of the art on breakwater design in Korea and directional effects on the stability of rubble mound structures. Proc. Int. Workshop on Adv. Design of Maritime Structures in the 21st Century, Port and Harbour Res. Inst., Yokosuka, pp. 142-151.

Shimosako, K. and Takahashi, S. (1999). Application of deformation-based reliability design for coastal structures. Proc. Int. Conf. Coastal Structures '99, A. A. Balkema, Spain, pp. 363-371.

Takayama, T. and Ikeda, N. (1993). Estimation of sliding failure probability of present breakwaters for probabilistic design. Rep. Port and Harbour Res. Inst. 31, 5, pp. 3-32.

Takayama, T. and Ikeda, N. (1994). Estimation of encounter probability of sliding for probabilistic design of breakwater. Proc. Wave Barriers in Deepwaters, Port and Harbour Res. Inst., Yokosuka, pp. 438-457.

Tanimoto, K., Haranaka, S. and Yamazaki, K. (1985). Experimental study of wave dissipating concrete blocks against irregular waves. Rep. Port and Harbour Res. Inst. 24, 2, pp. 85-121 (in Japanese).

van der Meer, J. W. (1988a). Deterministic and probabilistic design of breakwater armor layers. J. Waterway, Port, Coastal and Ocean Engrg. 114: 66-80.

van der Meer, J. W. (1988b). Stability of Cubes, Tetrapods and Accropods. Proc. Int. Conf. Breakwaters '88, American Soc. of Civil Engrs., pp. 59-68.

Vincent, C. L. and Briggs, M. J. (1989). Refraction-diffraction of irregular waves over a mound. J. Waterways, Port, Coastal and Ocean Engrg., American Soc. of Civil Engrs. 115: 269-284. 
Table 1

Averages and standard deviations of principal wave directions (unit: degrees)

\begin{tabular}{|c|c|c|c|c|c|c|c|c|c|c|}
\hline \multirow{2}{*}{$\begin{array}{c}\text { Location } \\
\text { No. }\end{array}$} & \multicolumn{7}{|c|}{ Number of occurrence $\left(H_{0}>3 \mathrm{~m}\right)$} & \multirow{2}{*}{$\begin{array}{c}\text { Average } \\
\left(\alpha_{p}\right)_{0} \\
(\mathrm{cw} \text { from } \mathrm{N})\end{array}$} & \multirow{2}{*}{$\begin{array}{l}\text { Average } \\
\left(\alpha_{p}\right)_{0} \\
\text { (ccw from } \\
\text { shore-normal } \\
\text { direction) }\end{array}$} & \multirow[t]{2}{*}{$\sigma_{\left(\alpha_{p}\right)_{0}}$} \\
\hline & NNW & $\mathrm{N}$ & NNE & $\mathrm{NE}$ & ENE & $\mathrm{E}$ & ESE & & & \\
\hline 53 & & 3 & 102 & 104 & 46 & 5 & & 40.5 & 49.5 & 18.2 \\
\hline 54 & & 7 & 80 & 126 & 48 & 5 & & 42.0 & 48.0 & 18.1 \\
\hline 55 & & 6 & 87 & 121 & 41 & 6 & & 41.0 & 49.0 & 18.1 \\
\hline 56 & & 8 & 59 & 133 & 37 & 3 & & 42.0 & 48.0 & 16.9 \\
\hline 58 & & 4 & 66 & 154 & 33 & 2 & 1 & 42.1 & 47.9 & 15.8 \\
\hline 59 & & 8 & 43 & 148 & 29 & 1 & & 42.3 & 17.7 & 15.2 \\
\hline 61 & 3 & 7 & 51 & 143 & 32 & 1 & & 41.0 & 19.0 & 17.0 \\
\hline 62 & & 3 & 16 & 134 & 50 & 1 & & 48.3 & 11.7 & 13.9 \\
\hline 63 & & 2 & 10 & 137 & 48 & 2 & 1 & 49.6 & 10.4 & 13.7 \\
\hline 64 & & 3 & 8 & 113 & 36 & 2 & 1 & 49.0 & 11.0 & 14.5 \\
\hline 65 & & & 3 & 58 & 51 & 2 & 1 & 55.8 & 4.2 & 14.0 \\
\hline 66 & & & 2 & 37 & 39 & 6 & 1 & 58.8 & 1.2 & 15.9 \\
\hline 67 & & & 2 & 2 & 32 & 3 & 1 & 66.9 & -6.9 & 14.7 \\
\hline
\end{tabular}


Table 2

Design wave heights and masses of Tetrapods

\begin{tabular}{|c|c|c|c|c|c|c|c|c|}
\hline \multirow{2}{*}{$\begin{array}{l}\text { Seabed slope } \\
\text { Water depth (m) }\end{array}$} & \multicolumn{8}{|c|}{$1 / 10$} \\
\hline & 7 & 9 & 11 & 13 & 15 & 17 & 19 & 21 \\
\hline Design wave height (m) & 8.97 & 9.82 & 10.48 & 10.79 & 10.33 & 9.88 & 9.58 & 9.36 \\
\hline Mass of Tetrapods (tf) & 78.4 & 103.0 & 124.8 & 136.6 & 119.8 & 104.8 & 95.5 & 89.3 \\
\hline Seabed slope & \multicolumn{8}{|c|}{$1 / 50$} \\
\hline Water depth (m) & 7 & 9 & 11 & 13 & 15 & 17 & 19 & 21 \\
\hline Design wave height (m) & 5.03 & 6.22 & 7.32 & 8.29 & 9.08 & 9.59 & 9.58 & 9.37 \\
\hline Mass of Tetrapods (tf) & 13.9 & 26.2 & 42.7 & 62.1 & 81.4 & 95.9 & 95.5 & 89.3 \\
\hline
\end{tabular}


Table 3

Test conditions

\begin{tabular}{ccccc}
\hline \hline Case No. & $s_{\max }$ & $\left(\alpha_{p}\right)_{0 d}($ deg. $)$ & $\sigma_{\left(\alpha_{p}\right)_{0}}($ deg. $)$ & $\alpha_{H_{1 / 3}}$ \\
\hline 1 & 1000 & 0 & 0 & -0.06 \\
2 & 20 & 0 & 0 & -0.06 \\
3 & 1000 & 20 & 0 & -0.06 \\
4 & 1000 & 0 & 15 & -0.06 \\
5 & 20 & 20 & 15 & 0.0 \\
6 & 20 & 48 & 17 & 0.0 \\
\hline \hline
\end{tabular}


Table 4

Number of occurrence of $H_{1 / 3 c}$ in different ranges of $H_{1 / 3 c}$ in water depth of 9 $\mathrm{m}$ on a beach with slope of $1 / 50$

\begin{tabular}{ccccccc}
\hline \hline \multirow{2}{*}{$\begin{array}{c}\text { Case } \\
\text { No. }\end{array}$} & \multicolumn{6}{c}{ Number of occurrence } \\
\cline { 2 - 7 } & $2.0-3.0$ & $3.0-4.0$ & $4.0-5.0$ & $5.0-6.0$ & $6.0-7.0$ & $7.0-8.0$ \\
\hline 1 & 6 & 1,586 & 31,427 & 55,880 & 10,900 & 201 \\
2 & 15 & 2,058 & 34,787 & 53,906 & 9,087 & 147 \\
3 & 15 & 1,769 & 33,506 & 54,786 & 9,765 & 159 \\
4 & 15 & 1,714 & 32,510 & 55,350 & 10,243 & 168 \\
5 & 15 & 1,035 & 20,773 & 58,607 & 18,891 & 679 \\
6 & 48 & 2,643 & 26,816 & 55,457 & 14,633 & 403 \\
\hline \hline
\end{tabular}


Table 5

Same as Table 4, but for water depth of $19 \mathrm{~m}$

\begin{tabular}{ccccccc}
\hline \hline \multirow{2}{*}{$\begin{array}{c}\text { Case } \\
\text { No. }\end{array}$} & $2.0-3.0$ & $3.0-4.0$ & $4.0-5.0$ & $5.0-6.0$ & $6.0-7.0$ & $7.0-8.0$ \\
\hline 1 & 44 & 2,431 & 16,591 & 29,169 & 24,927 & 14,867 \\
2 & 50 & 2,994 & 18,312 & 30,414 & 24,568 & 13,728 \\
3 & 50 & 2,771 & 17,370 & 29,899 & 24,727 & 14,255 \\
4 & 44 & 2,636 & 17,076 & 29,511 & 24,864 & 14,512 \\
5 & 21 & 1,896 & 15,190 & 29,414 & 26,218 & 15,331 \\
6 & 49 & 4,019 & 22,852 & 32,518 & 22,708 & 11,155 \\
\hline \hline Case & \multicolumn{5}{c}{ Number of occurrence } \\
No. & $8.0-9.0$ & $9.0-10.0$ & $10.0-11.0$ & $11.0-12.0$ & $12.0-13.0$ & $13.0-14.0$ \\
\hline 1 & 7,290 & 3,183 & 1,105 & 351 & 39 & 3 \\
2 & 6,246 & 2,569 & 839 & 268 & 9 & 3 \\
3 & 6,760 & 2,867 & 967 & 307 & 24 & 3 \\
4 & 6,971 & 2,987 & 1,037 & 329 & 30 & 3 \\
5 & 7,285 & 3,064 & 1,139 & 352 & 87 & 3 \\
6 & 4,389 & 1,609 & 496 & 172 & 30 & 3 \\
\hline \hline
\end{tabular}




\section{Captions of figures}

1. Flow chart for computation of total damage level within one lifetime [modified from Hanzawa et al. (1996)].

2. Location of wave hindcasting (from http://www.kordi.re.kr).

3. Comparison of expected damage level between present model and Hanzawa et al.'s (1996) model.

4. Comparison of expected damage level between $\alpha_{H_{1 / 3}}=-0.13$ and $\alpha_{H_{1 / 3}}=-0.06$.

5. Comparison of wave height variation with water depth between unidirectional waves $\left(s_{\max }=1000\right)$ and directional waves $\left(s_{\max }=20\right)$.

6. Change of expected damage level due to effect of directional spreading.

7. Change of expected damage level due to effect of wave refraction.

8. Change of expected damage level due to effect of variation of principal wave direction.

9. Change of expected damage level due to all effects of directional spreading, wave refraction, and variation of principal wave direction.

10. Same as Fig. 9, but for use of field data at locations 53 to 58 in Fig. 2.

11. Ratio of number of occurrence of $H_{1 / 3 c}$ to that of Case 1 in different ranges of $H_{1 / 3 c}$ in water depth of $9 \mathrm{~m}$ on a beach with slope of 1/50.

12. Same as Fig. 11, but for water depth of $19 \mathrm{~m}$. 
Fig. 1

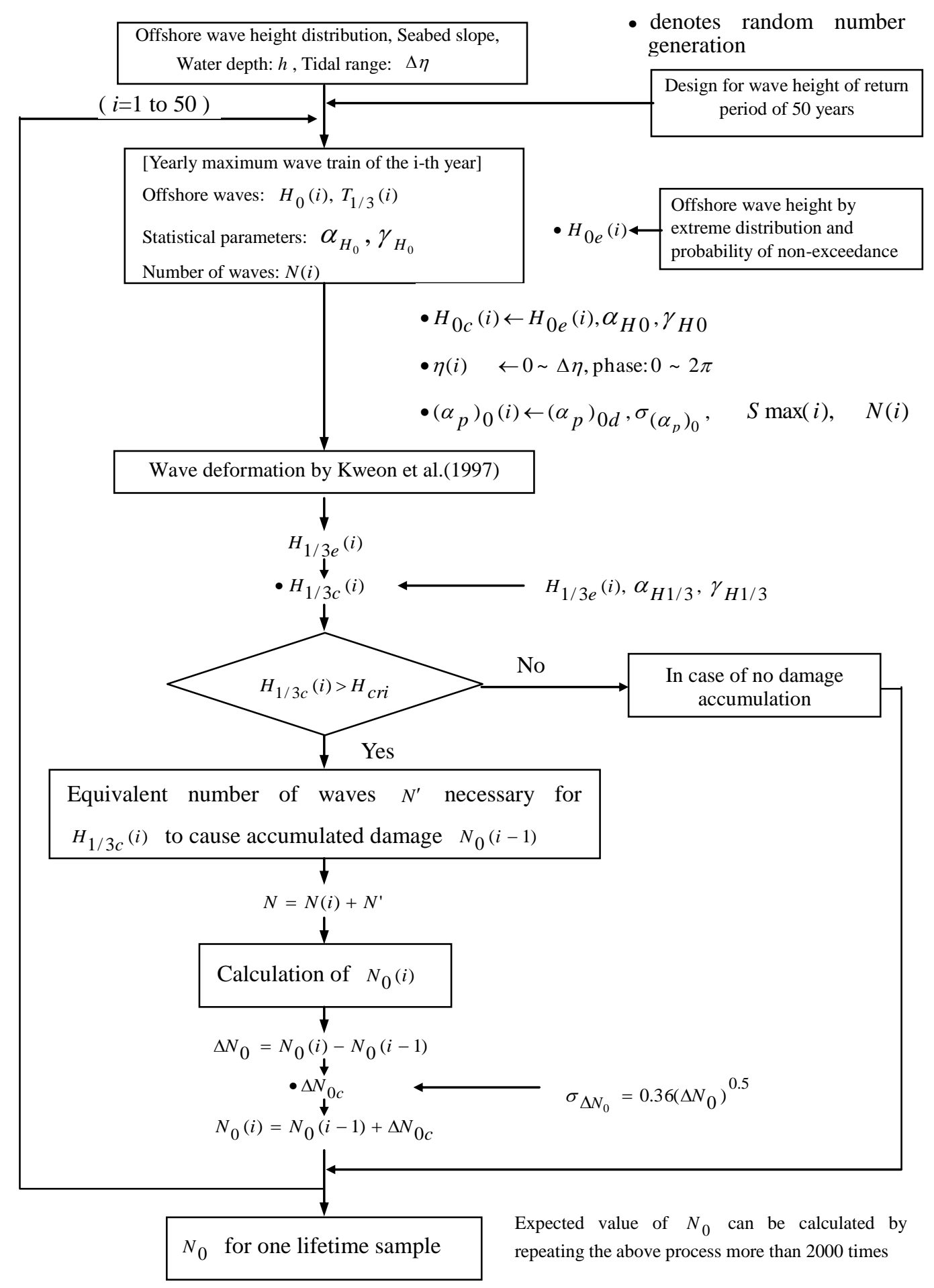


Fig. 2

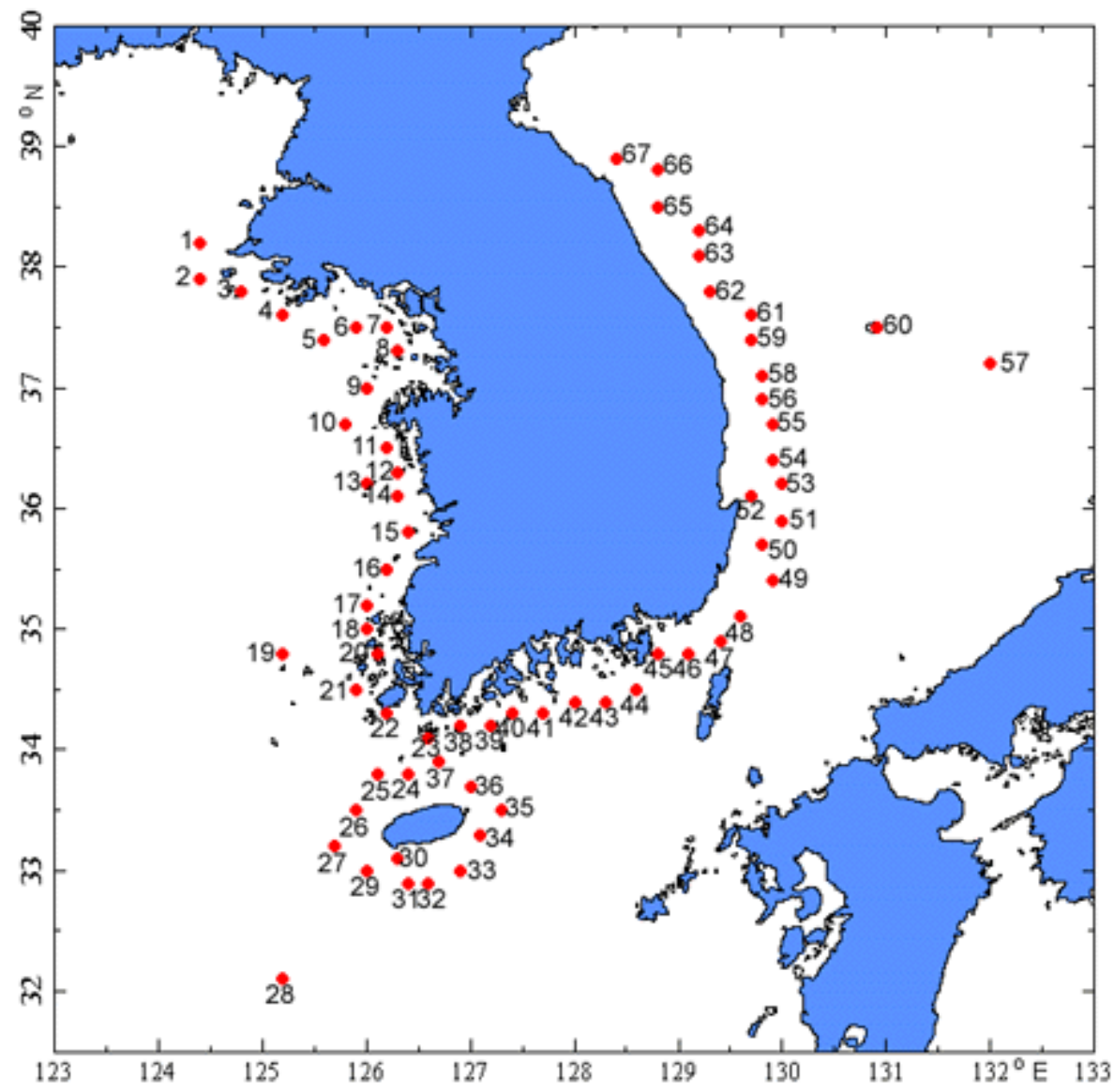


Fig. 3

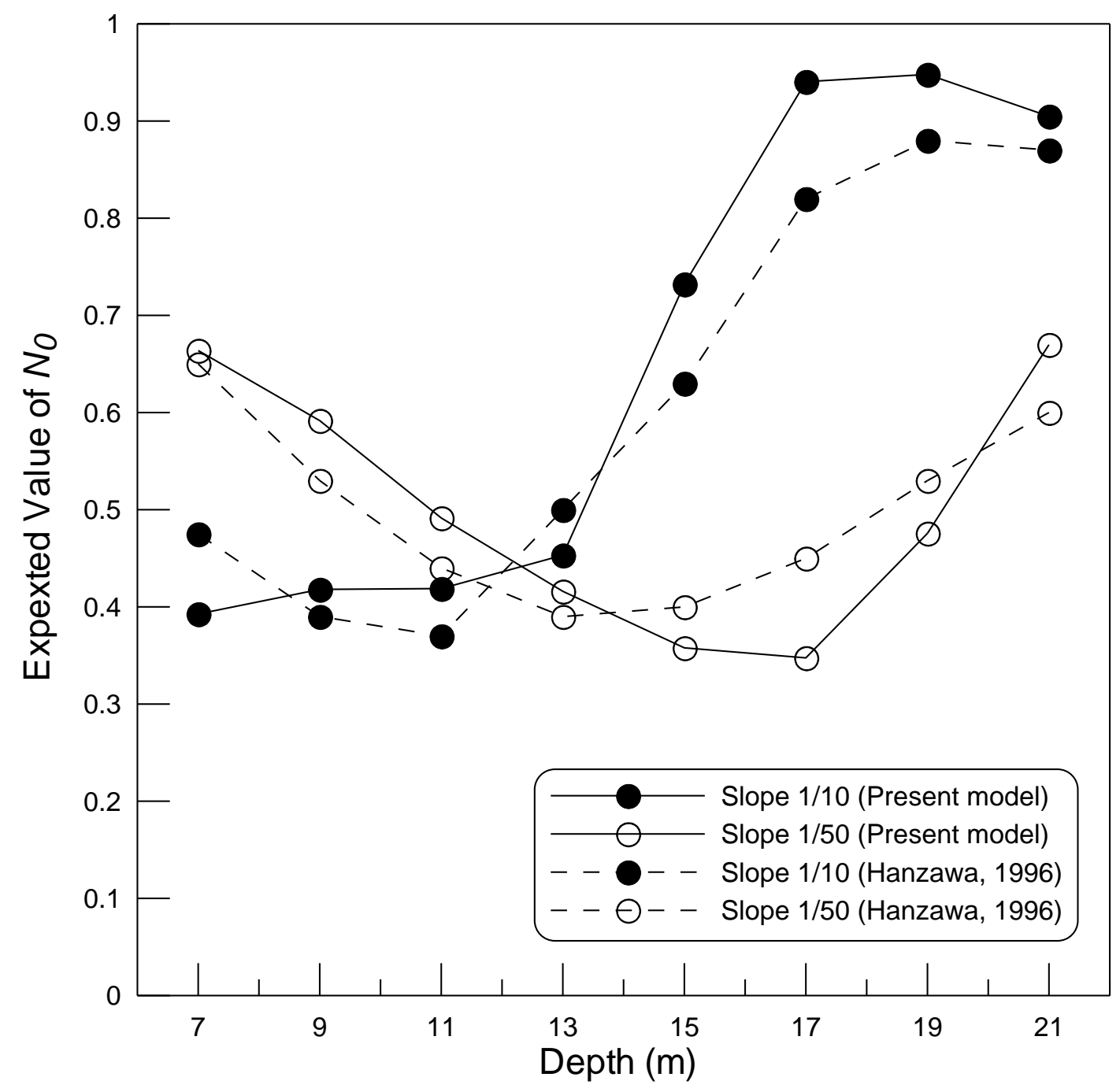


Fig. 4

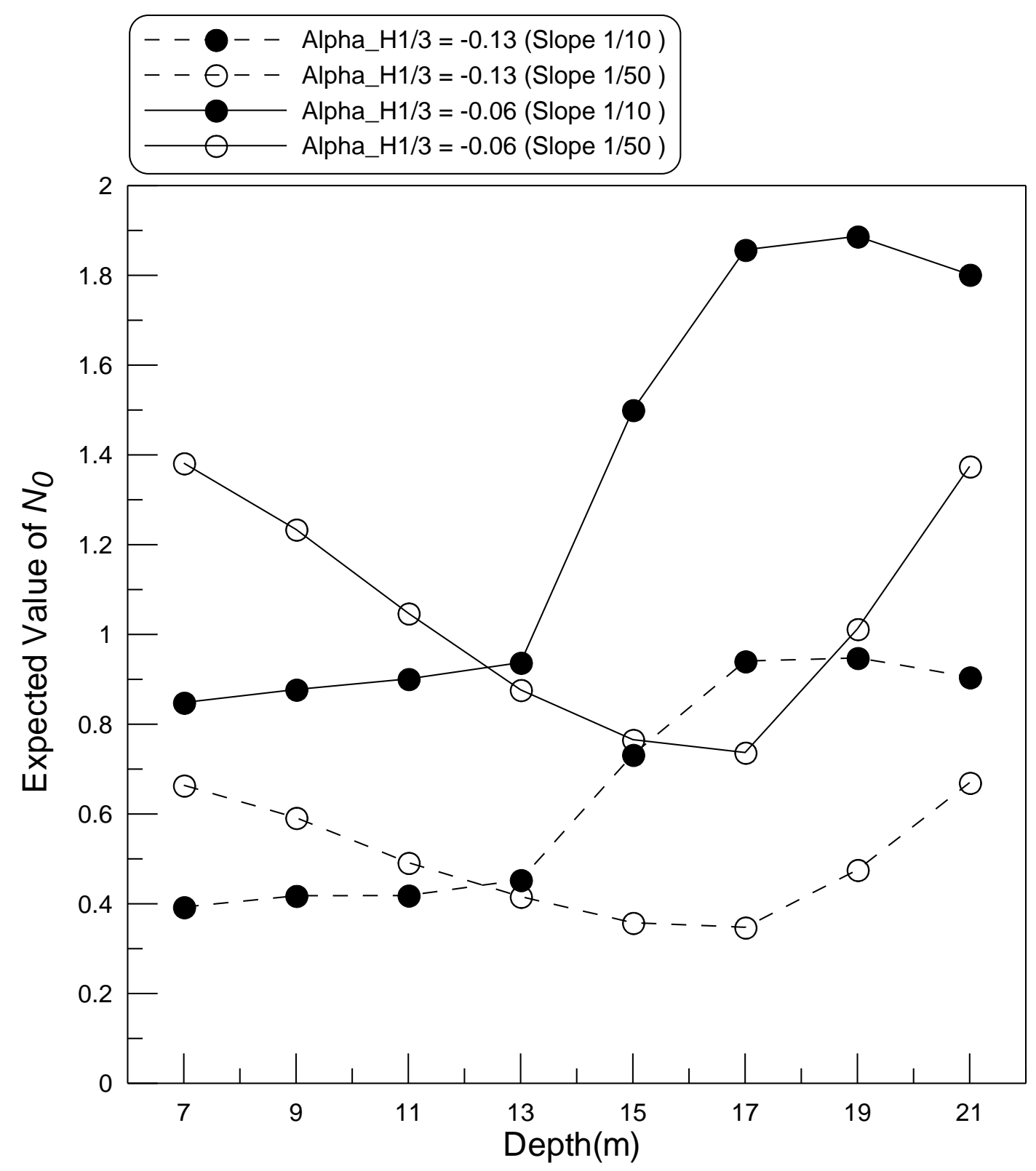


Fig. 5

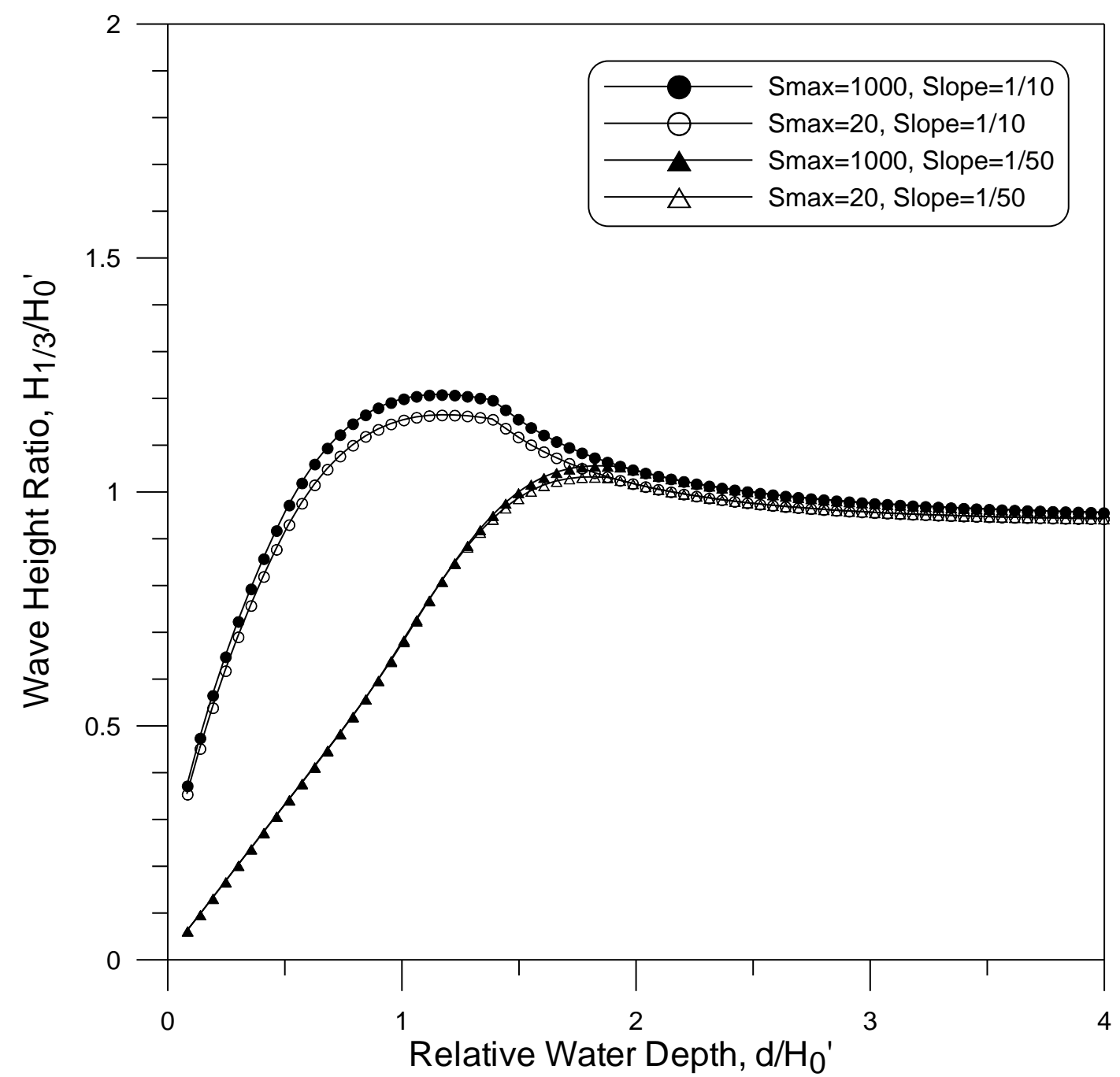


Fig. 6

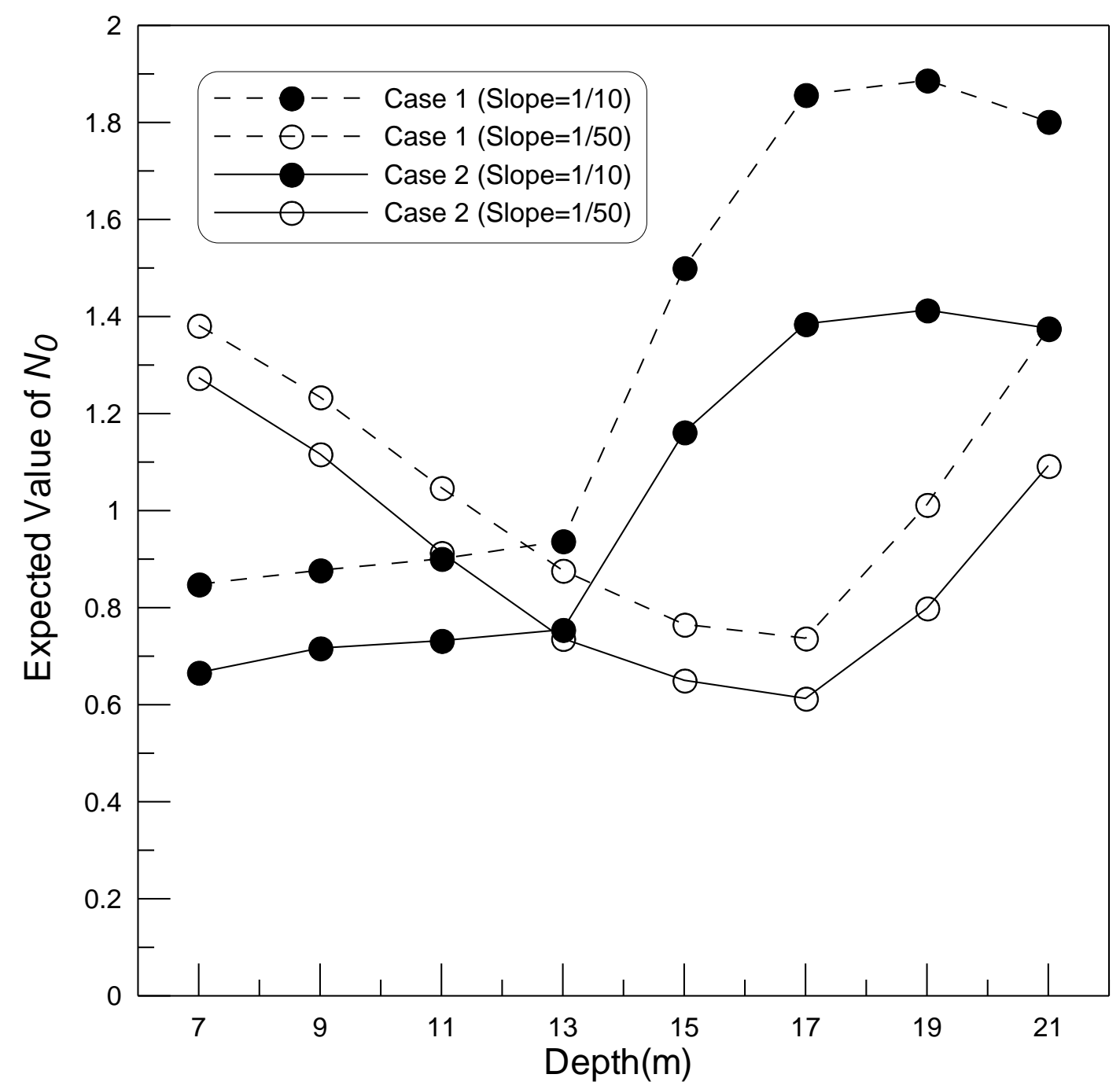


Fig. 7

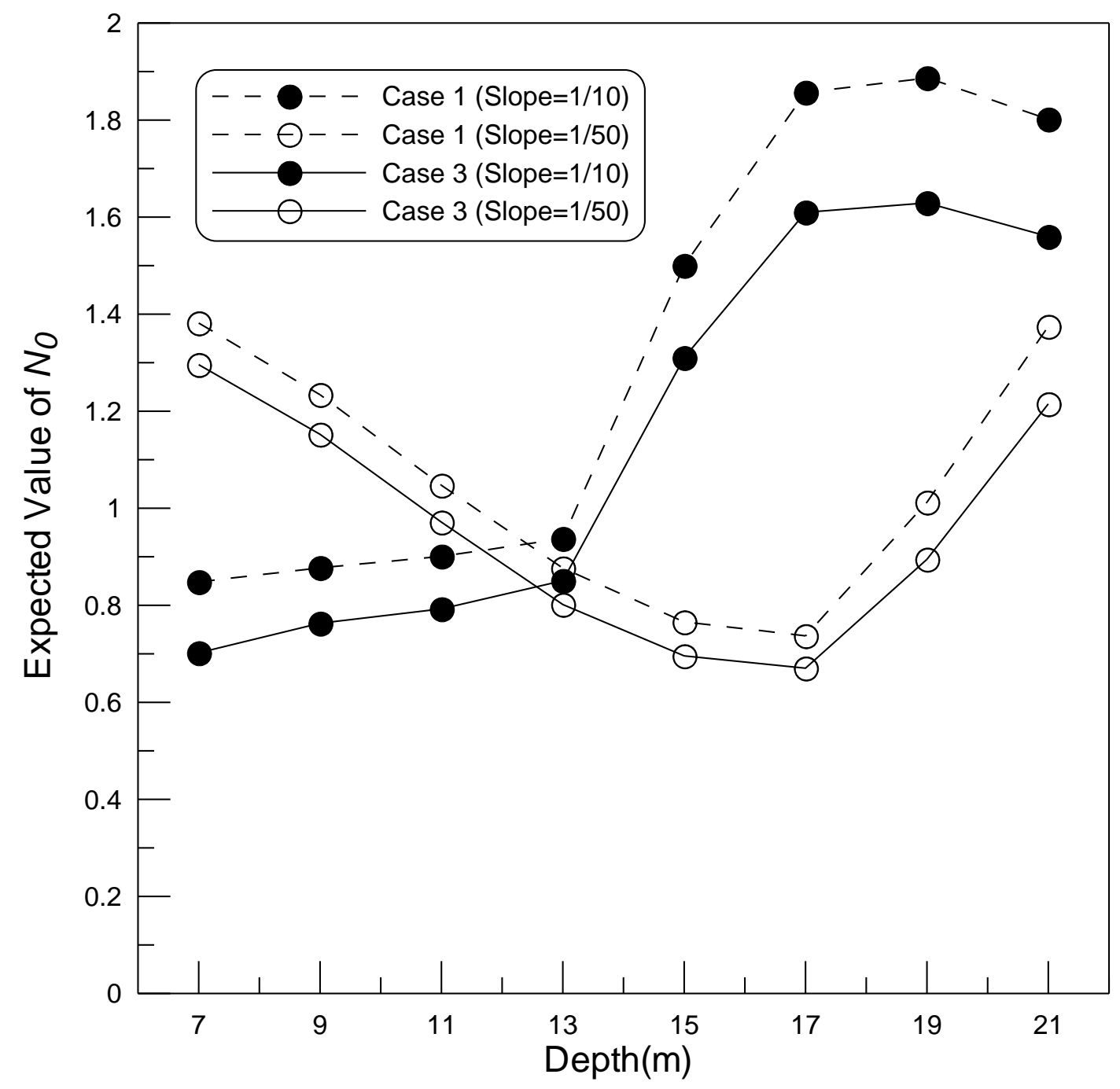


Fig. 8

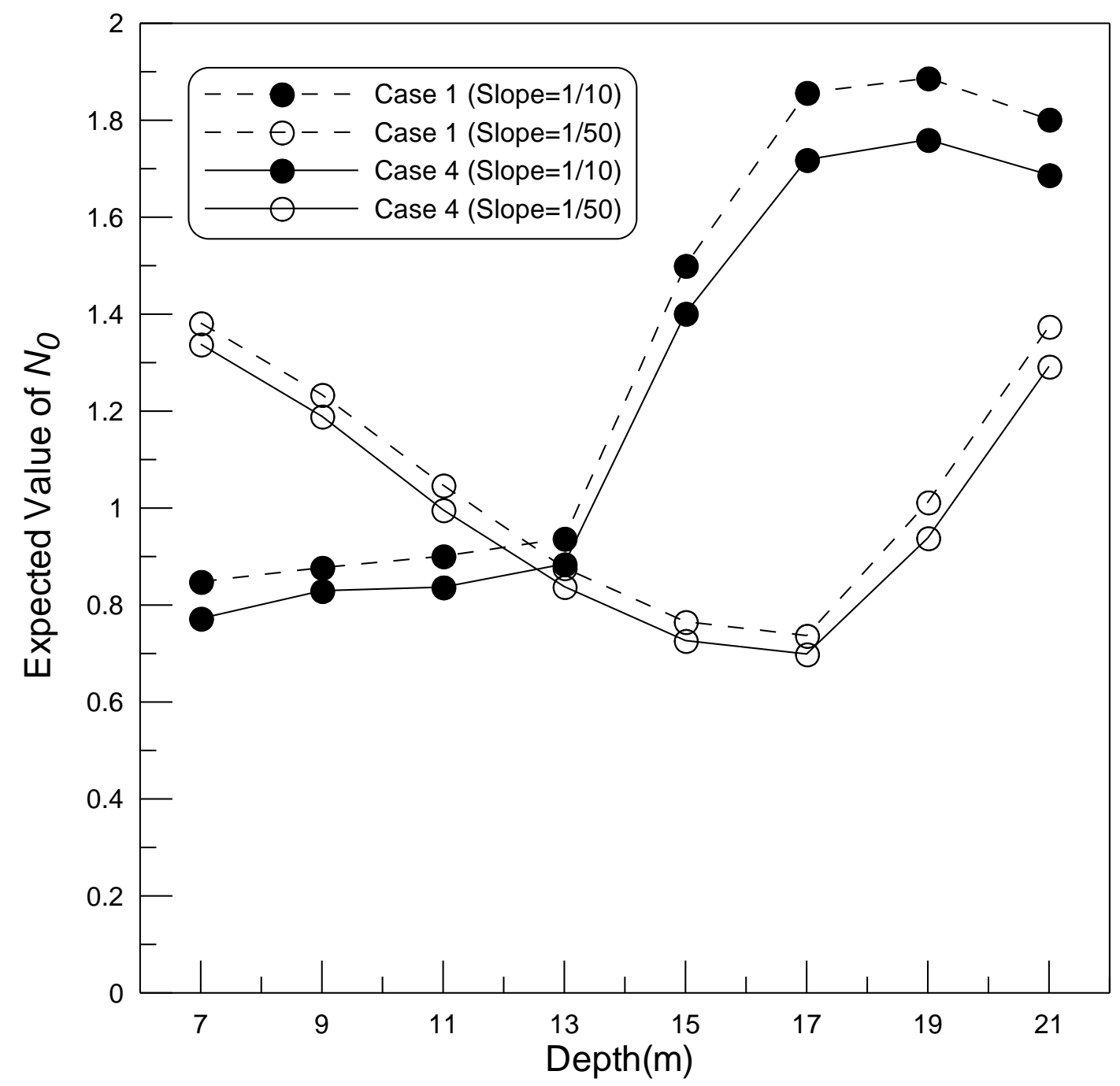


Fig. 9

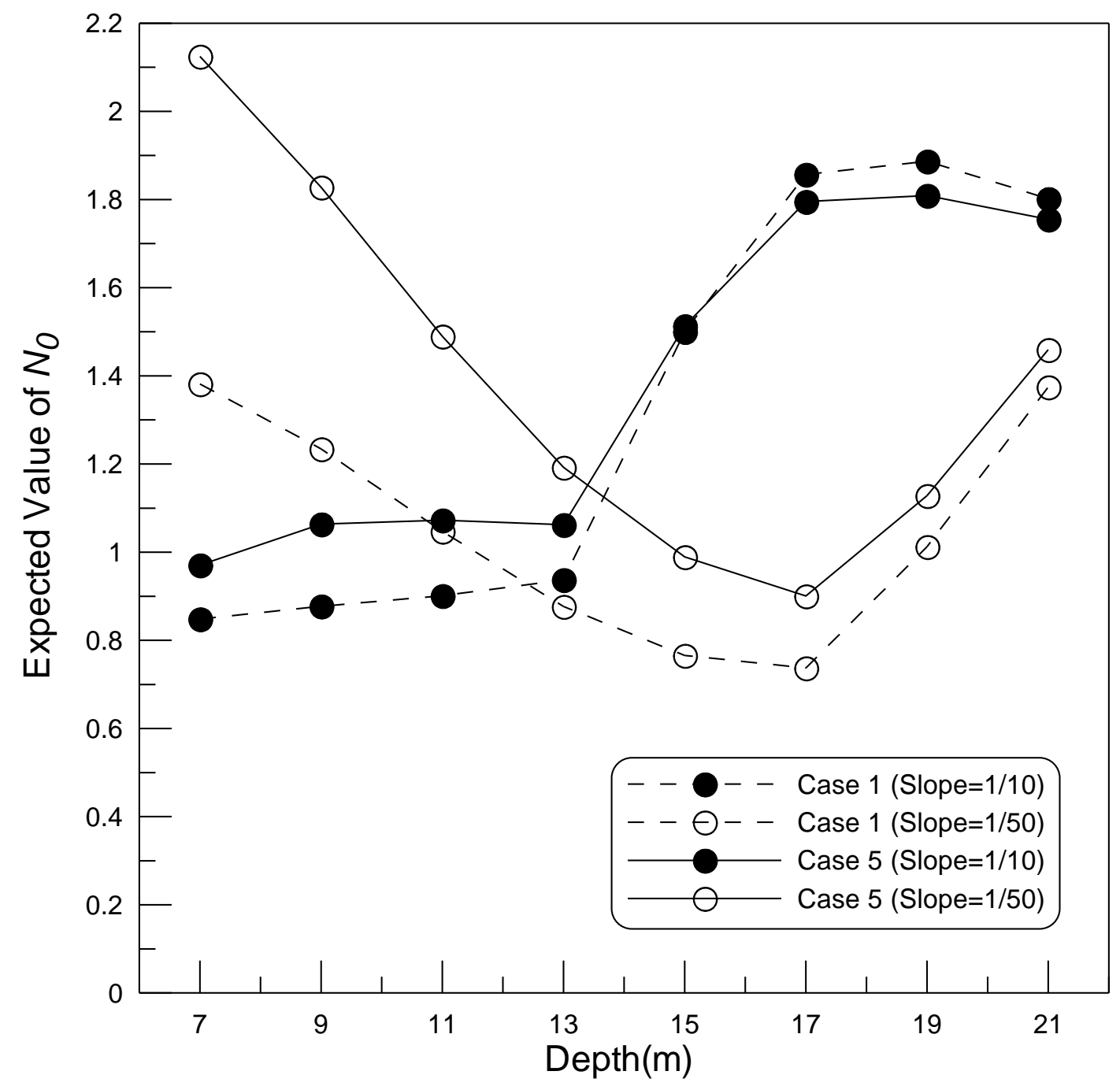


Fig. 10

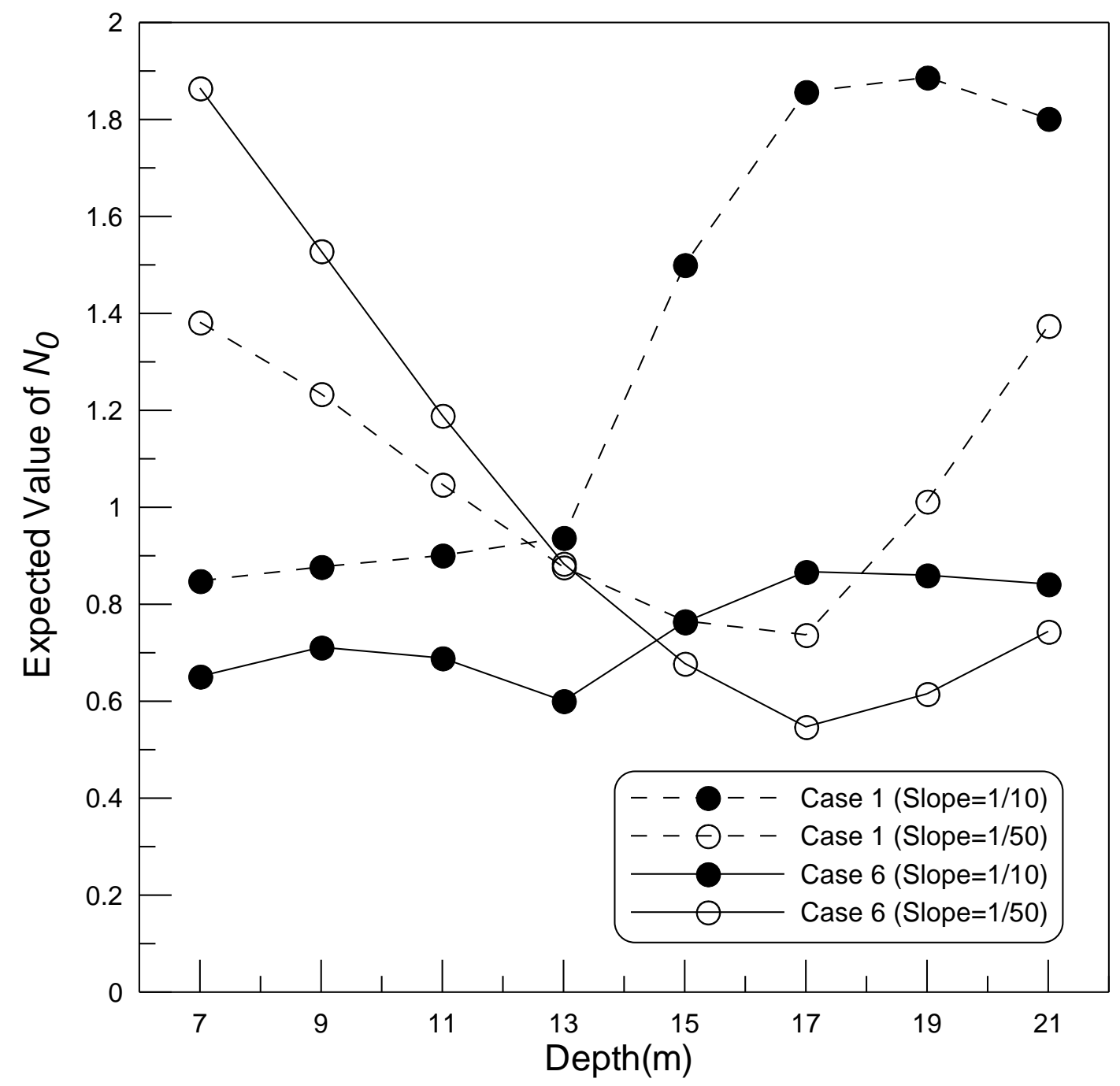


Fig. 11

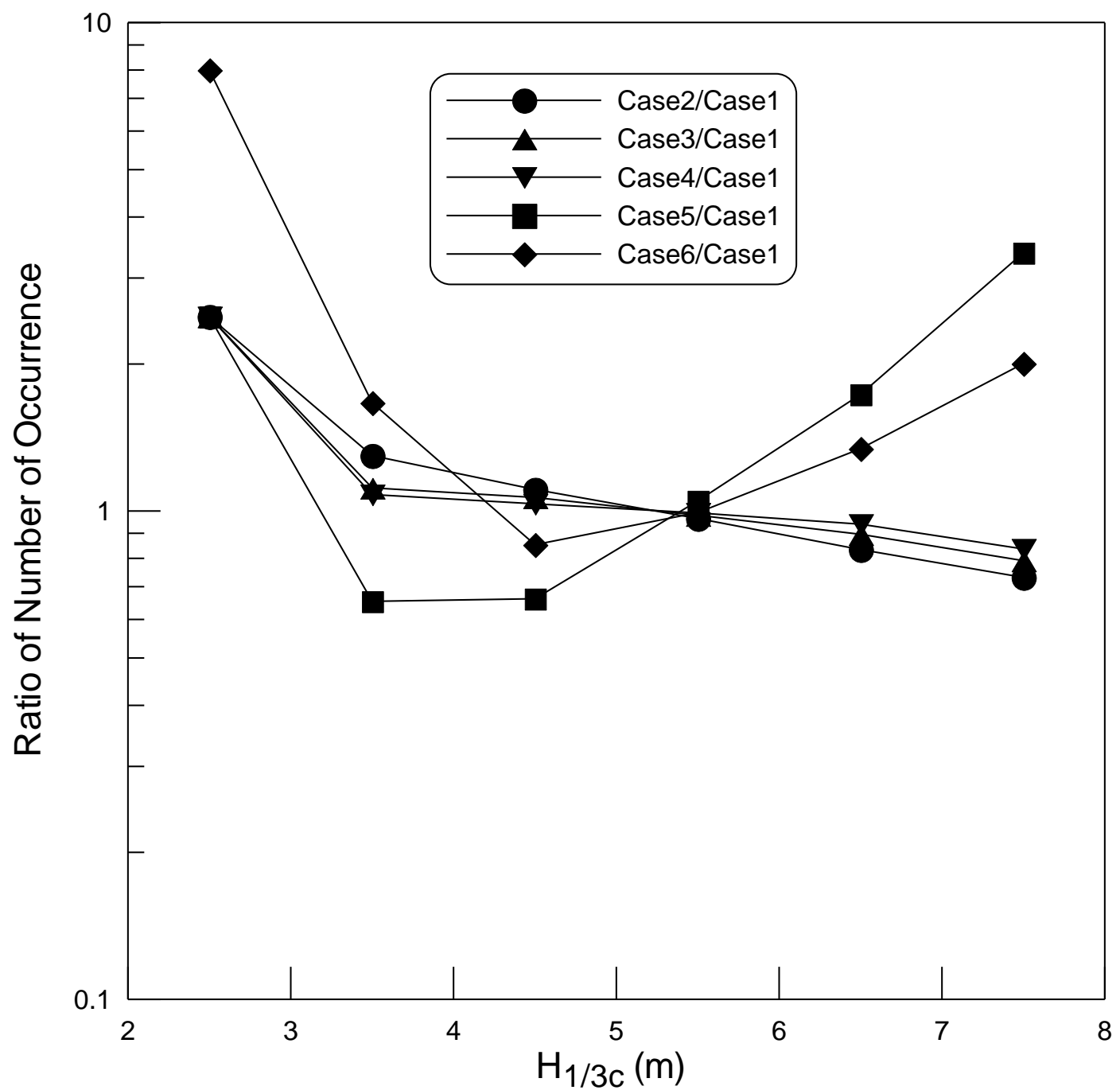


Fig. 12

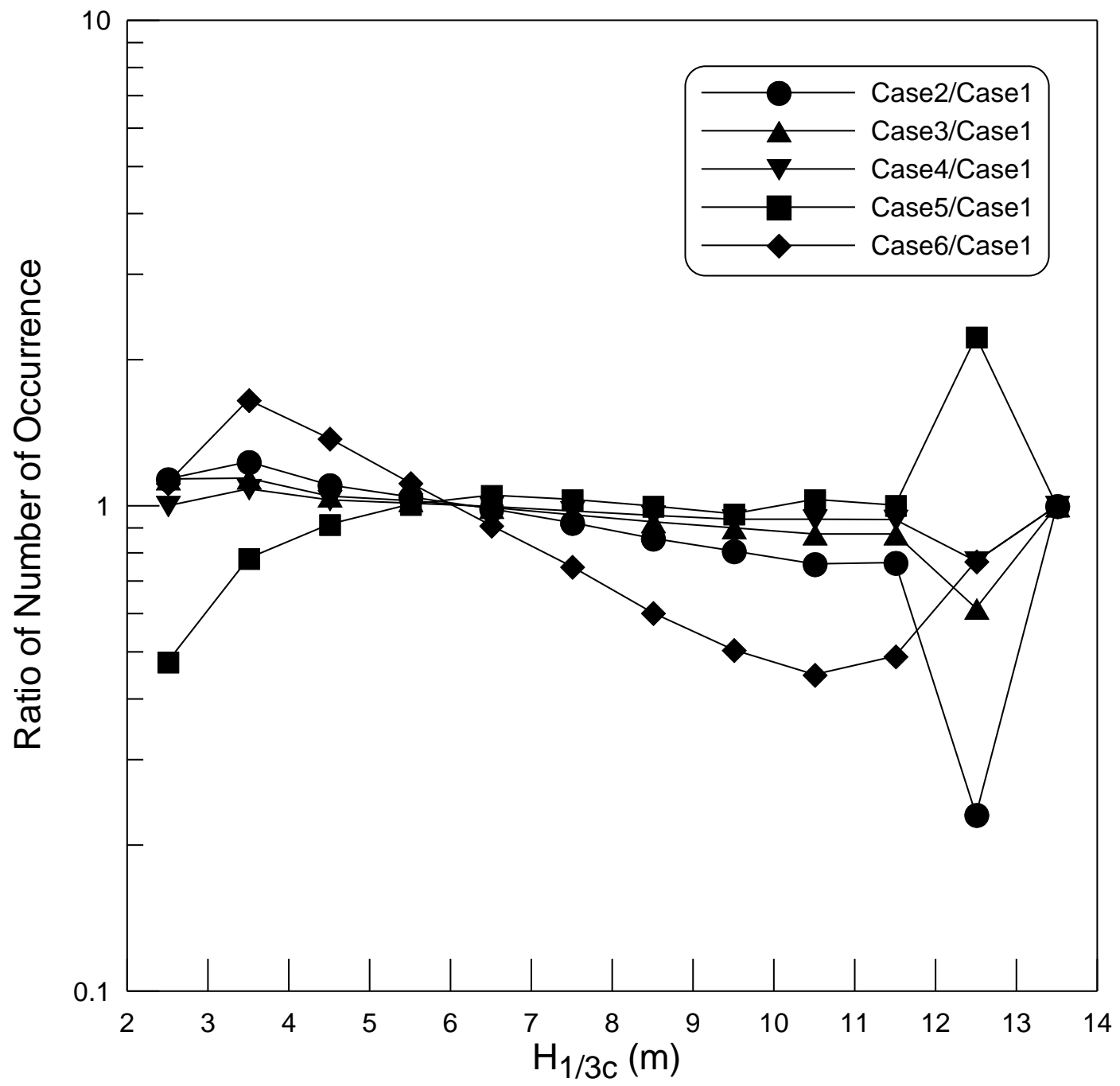

